\title{
Cross-Training Exercises: Crossroads to Successful Prevention of Chronic Diseases
}

\author{
Daniel R. Machin and Hirofumi Tanaka* \\ Cardiovascular Aging Research Laboratory, Department of Kinesiology and Health Education, University of Texas at Austin, USA
}

The prevalence of many chronic diseases increases markedly with advancing age. With an ever increasing aging population accompanied by steadily rising costs of medical care, prevention and treatment for age-related chronic diseases has become an extremely important topic, especially for those older adults who may be retired or are living on a fixed income. The first-line approach for preventing and treating age-related chronic diseases is increases in physical activity $[1,2]$. Although regular exercise does not appear to extend longevity [3], there is substantial evidence demonstrating that regular physical activity decreases the risk of premature death $[1,2,4]$. Over the years, habitual exercise has become the biggest patron for the famous quote of Benjamin Franklin "An ounce of prevention is worth a pound of cure".

While there are many different types of exercise practiced by the general public, resistance training and endurance training are the two most common forms of exercise [4]. Both exercise modes can significantly and independently improve health outcomes in older adults by reducing total and abdominal body fat while preserving fat free mass and improving metabolic and cardiovascular risk profiles (e.g., higher HDL cholesterol, lower triglycerides and blood glucose) [1]. However, one could argue that both types of exercise should be performed to gain the maximum health benefits. Resistance training can increase muscular strength and power as well as bone mineral density [5]. The number one reason for not starting exercise programs among sedentary adults is a lack of time to exercise. But the current guideline for resistance training calls for only one set of weight training exercises performed per session, and some of the benefits can be achieved with as little as one bout of resistance training per week [5]. While muscular strength and power is increased with resistance training, this is not a training adaptation gained through endurance exercise. This is easily conceivable when one looks at the skin and bone appearance of endurance-trained runners. Conversely, maximal aerobic capacity does not increase to the same extent in resistance training, as it does through endurance exercise [6]. Endurance exercise, on the other hand, has its own unique set of benefits associated with it. Older adults can increase maximal aerobic capacity, increase or maintain bone mineral density (dependent on mode of exercise), and enhance vascular function including endothelial function and arterial stiffness $[1,7]$. Because some of the training effects are very distinct, a combination of both resistance training and endurance training has become a clinically important strategy for prevention of chronic diseases [8]. This is particularly so when one considers the research findings that strenuous resistance training increases arterial stiffness [9] and that a simultaneous performance of endurance training effectively counteracts the arterial stiffening effect of strenuous resistance training [10].

In recent years, vigorous endurance exercise is increasingly recommended, as benefits associated with endurance exercise may be greater as the intensity of exercise increases. High-intensity interval training exercise is an effective and efficient form of exercise, as the time spent exercising is less than traditional continuous endurance exercise. Maximal aerobic capacity [11], baroreflex sensitivity [12], and insulin sensitivity [13] are increased to a greater extent following interval exercise than may be achievable during continuous endurance exercise. The generalizability of adding interval training to an elderly population, as a "one size fits all" prescription, should be met with caution because of the increased risk of orthopedic injuries. Incorporation of low-impact non-weight bearing exercise like cycling may be an approach taken by an older individual who is injury prone to perform interval training. However, cycling exercise may reduce, rather than increase ,bone mineral density presumably through a loss of calcium in sweat [14], and it may increase the overall risk of hip fracture. Although decreased ability of older individuals to sweat and thermo regulate [15] may make this a mute point, this can't be ignored for postmenopausal women who are especially prone to osteoporosis. Therefore, the addition of resistance training or moderate intensity weight-bearing exercise to non-weight bearing interval training may counteract the increased risk of injury, while maintaining or even increasing benefits of exercise.

As an individual grows older, the risk of musculoskeletal injury during exercise may be increased [16]. In regards to land-based weightbearing exercise (e.g. walking or jogging), increases in exercise intensity may exacerbate exercise-related injuries [16]. The actual risk of injury is difficult to ascertain in the exercise training studies, as individuals with previous injury are often excluded from the participation. However, it has been estimated that about $25 \%$ of people who engage in exercise have some sort of injury within the calendar year. In an early study, older individual's rate of injury during jogging exercise was as high as $45 \%$ [17]. A more alarming statistics is that one-third of people who were injured during exercise will stop exercising altogether [18]. Clearly, a greater rate of orthopedic injuries in the elderly must be considered carefully when constructing exercise programs.

In conclusion, it is clear that increases in physical activity are beneficial for the primary and secondary prevention of chronic diseases. In the past, aerobic exercise was a predominant form of exercise practiced and recommended. In more recent years, the incorporation of resistance training and/or high-intensity interval training is increasingly recommended even for older adults. After all, there are no clear or distinct differences in ways that exercise is prescribed to young and older individuals. However, a greater rate of orthopedic injury in older adults is an important consideration when prescribing exercise programs.

*Corresponding author: Hirofumi Tanaka, Department of Kinesiology and Health Education, University of Texas at Austin, USA, Tel: 512-232-4801; Fax: 512-471-0946; E-mail: htanaka@austin.utexas.edu

Received March 16, 2012; Accepted March 19, 2012; Published March 24, 2012

Citation: Machin DR, Tanaka H (2012) Cross-Training Exercises: Crossroads to Successful Prevention of Chronic Diseases. J Gerontol Geriat Res 1:e103. doi:10.4172/2167-7182.1000e103

Copyright: (c) 2012 Machin DR, et al. This is an open-access article distributed under the terms of the Creative Commons Attribution License, which permits unrestricted use, distribution, and reproduction in any medium, provided the original author and source are credited. 
Citation: Machin DR, Tanaka H (2012) Cross-Training Exercises: Crossroads to Successful Prevention of Chronic Diseases. J Gerontol Geriat Res 1:e103. doi:10.4172/2167-7182.1000e103

\section{References}

1. Chodzko-Zajko WJ, Proctor DN, Fiatarone Singh MA, Minson CT, Nigg CR, et al. (2009) American College of Sports Medicine position stand. Exercise and physical activity for older adults. Med Sci Sports Exerc 41: 1510-1530.

2. Thompson PD, Buchner D, Pina IL, Balady GJ, Williams MA, et al. (2003) Exercise and physical activity in the prevention and treatment of atherosclerotic cardiovascular disease: a statement from the Council on Clinical Cardiology (Subcommittee on Exercise, Rehabilitation, and Prevention) and the Council on Nutrition, Physical Activity, and Metabolism (Subcommittee on Physical Activity). Circulation 107: 3109-3116.

3. Holloszy JO, Kohrt, W.M. (1995) Exercise. Handbook of Physiology Section 11 Aging. Oxford: University Press.pp633-666

4. Mazzeo RS, Tanaka H (2001) Exercise prescription for the elderly: current recommendations. Sports Med. 31: 809-818.

5. Taaffe DR, Duret C, Wheeler S, Marcus R (1999) Once-weekly resistance exercise improves muscle strength and neuromuscular performance in older adults. J Am Geriatr Soc 47: 1208-1214.

6. Hickson RC, Rosenkoetter MA, Brown MM (1980) Strength training effects on aerobic power and short-term endurance. Med Sci Sports Exerc 12: 336-339.

7. Seals DR, Desouza CA, Donato AJ, Tanaka H (2008) Habitual exercise and arterial aging. J Appl Physiol 105: 1323-1332.

8. Tanaka H, Swensen T (1998) Impact of resistance training on endurance performance. A new form of cross-training? Sports Med 25: 191-200.

9. Miyachi M, Kawano H, Sugawara J, Takahashi K, Hayashi K, et al. (2004) Unfavorable effects of resistance training on central arterial compliance: a randomized intervention study. Circulation 110: 2858-2863.
10. Kawano H, Tanaka H, Miyachi M (2006) Resistance training and arteria compliance: keeping the benefits while minimizing the stiffening. J Hypertens 24: 1753-1759.

11. Makrides L, Heigenhauser GJ, Jones NL (1990) High-intensity endurance training in 20- to 30- and 60- to 70-yr-old healthy men. J Appl Physiol 69: 1792 1798.

12. Pichot V, Roche F, Denis C, Garet M, Duverney D, et al. (2005) Interval training in elderly men increases both heart rate variability and baroreflex activity. Clin Auton Res 15: 107-115.

13. DiPietro L, Dziura J, Yeckel CW, Neufer PD (2006) Exercise and improved insulin sensitivity in older women: evidence of the enduring benefits of higher intensity training. J Appl Physiol 100: 142-149.

14. Barry DW, Kohrt WM (2008) BMD decreases over the course of a year in competitive male cyclists. J Bone Miner Res 23: 484-491.

15. Kenney WL, Munce TA (2003) Invited review: aging and human temperature regulation. J Appl Physiol 95: 2598-2603.

16. McKean KA, Manson NA, Stanish WD (2006) Musculoskeletal injury in the masters runners. Clin J Sport Med 16: 149-154.

17. Pollock ML, Carroll JF, Graves JE, Leggett SH, Braith RW, et al. (1991) Injuries and adherence to walk/jog and resistance training programs in the elderly. Med Sci Sports Exerc 23: 1194-1200.

18. Hootman JM, Macera CA, Ainsworth BE, Addy CL, Martin M, et al. (2002) Epidemiology of musculoskeletal injuries among sedentary and physically active adults. Med Sci Sports Exerc 34: 838-844. 